\title{
Data reduction algorithms for fully quantitative analysis of clinopyroxene by LA ICPMS
}

\author{
I. Belousov ${ }^{1}$, L. DANYUSHEVSKY ${ }^{1}$, E. DRAAYERS ${ }^{2}$ AND \\ P. OLIN ${ }^{1}$ \\ ${ }^{1}$ TMVC, CODES, University of Tasmania, Hobart, Australia, \\ Ivan.Belousov@utas.edu.au \\ ${ }^{2}$ Earth Sciences, University of Tasmania, Hobart, Australia
}

The conventional approach to accurate mineral analysis by LA ICPMS requires matrix-matched reference materials and knowledge of concentration of the Internal Standard Element which is commonly determined by EPMA or assumed from stoichiometry when the mineral of interest is not a solid solution. We have developed a method for analysis of clinopyroxene that does not involve either of the above two requirements. The primary calibration is performed using the NIST612 glass reference material [1]. NIST612 glass is analysed using a large laser beam (50- $80 \mathrm{um})$ to ensure that the instrument performance during the analytical session (the changing yield with time) is characterised with the best possible uncertainty. Secondary reference material (glasses of broadly basaltic compositions, GSD-1G and BCR-2G [2]) are analysed throughout the session at the same analytical conditions as the unknowns, and are used to perform corrections to the primary calibration to achieve accurate results, however an additional correction factor for $\mathrm{Si}$ concentration was required to achieve stoichiometric compositions of clinopyroxene. Concentrations of all elements are converted to oxides and normalised to a sum of $100 \%$, thus not requiring a prior knowledge of the Internal Standard Element concentration.

We will also present the compositions of clinopyroxenes from lavas erupted on several subduction zone volcanoes from Philippines arc (Mayon and Iriga volcanoes) and KurilKamchatka arc (Tolbachik, Kluchevskoy and Karymsky and Tyatya volcanoes) and compare them to the compositions of clinopyroxenes from boninites of the Hunter ridge and Tonga arc, in order to demonstrate that the clinopyroxene compositions can be used to better constrain the compositions of mantle sources of the primary melts from which these pyroxenes have crystallised.

[1] Jochum et al., 2011. GGR, v.35 (4), pp. 397-429.

[2] Jochum et al., 2005. GGR, v.29 (3), pp. 315-331. 